\title{
VITAMIN A DEFICIENCY IN LAENNEC'S CIRRHOSIS. THE RELATIVE SIGNIFI- CANCE OF THE PLASMA VITAMIN A AND CAROTENOID LEVELS AND THE DARK ADAPTATION TIME ${ }^{1}$
}

\author{
By CHARLES HAIG aNd ARTHUR J. PATEK, JR. \\ (From the Research Service, First Medical Division, Welfare Hospital, New York City Depart- \\ ment of Hospitals, and the Department of Medicine, College of Physicians \\ and Surgeons, Columbia University, New York City)
}

(Received for publication December 11, 1941)

Recent studies (1 to 9) have reported the occurrence of vitamin A deficiency in patients having cirrhosis of the liver. It has also been shown that a lowering of the amount of vitamin $A$ available to the tissues may result from reduced vitamin A intake (10 to 14 ), and from faulty gastro-intestinal absorption $(6,15,16)$, especially when associated with jaundice (16). It is known, moreover, that febrile states reduce the level of vitamin $A$ in the blood $(17,18)$. Since both faulty gastro-intestinal absorption and fever (19) may occur in Laennec's cirrhosis, it is essential in a study of vitamin A deficiency in relation to this disease that these factors be controlled. In many of the published studies of the subject, either the appropriate controls are lacking, or the conditions bearing on these factors are unspecified.

In previous papers data were presented which revealed that $(a)$ patients with cirrhosis of the liver may have greatly delayed dark adaptation which is improved by massive daily doses of vitamin A $(3,4)$; (b) there is no evidence in such patients of a causal relation between the level of vitamin $\mathrm{A}$ in the blood and the dark adaptation time $(20) ;(c)$ the vitamin A concentration in the liver of rats with carbon tetrachloride cirrhosis was half that of normal rats fed the same amount of food and of vitamin A (21).

It is our present purpose to compare the dark adaptation time and the blood plasma concentration of vitamin A and of total carotenoid found in patients with Laennec's cirrhosis with those found in normal persons and in patients with certain other diseases.

\section{METHODS}

Dark adaptation measurements and determinations of the concentration of vitamin A and of total carotenoid in

\footnotetext{
1 Preliminary accounts of these measurements were presented to the American Society of Zoologists in December, 1941 (Anat. Rec., 1941, 81, Suppl., 123, 124).
}

the blood plasma and in the liver were made by methods described elsewhere (20). Plasma vitamin A levels were expressed as international units (I. U.) per $100 \mathrm{ml}$. of plasma, plasma carotenoid levels as micrograms ( $\mu \mathrm{gm}$. per $100 \mathrm{ml}$. of plasma, and liver vitamin A and carotenoid contents as I.U. and $\mu \mathrm{gm}$., respectively, per gram of fresh tissue. The parameter of the dark adaptation function employed for comparison among the various subjects, called the dark adaptation time, is defined as the time in minutes required for the visual threshold to attain a value of 5.50 (in $\log$ micromicrolamberts). This quantity records variations in either the rate of adaptation or in the threshold level (20). The concentration of total cholesterol in the plasma was also determined, using the method of Bloor, Pelkin, and Allen (22).

All of the patients studied received a high caloric diet providing a quantity of vitamin A estimated (23) at approximately 14,000 I.U. per day in addition to adequate amounts of other vitamins and minerals. No obvious pathology of the eye was observed in any of the patients. None of the patients with Laennec's cirrhosis had jaundice or diarrhea at the time of the study. In most of these cases it was possible to determine the plasma vitamin A and carotenoid levels during completely afebrile periods.

The patients were divided for comparison into the following 3 clinical groups as judged by physical signs and laboratory tests: (1) patients with decompensated ${ }^{2}$ Laennec's cirrhosis, (2) patients with compensated Laennec's cirrhosis, and (3) patients with certain other diseases (hospital controls). The results of the blood analyses and visual tests on these groups were compared with similar data previously obtained (20) in normal subjects.

The ratio of the concentration of plasma vitamin $A$ to the concentration of plasma carotenoid (A/C ratio) was

2 Patients with "decompensated" cirrhosis were bedridden. They generally gave the history of recent weight loss and failing strength. Examination showed a palpable liver and spleen, ascites, edema, and signs of collateral venous circulation. Laboratory tests gave evidence of severe derangement of liver function.

Patients with "compensated" cirrhosis were ambulatory. They felt well. Although the liver and spleen were usually palpable, there was no ascites, edema, or jaundice. Laboratory findings were less abnormal than in the decompensated group. The clinical differences between these groups are described more fully in another paper (19). 
also compared among the 4 groups of subjects. If in Laennec's cirrhosis the in vivo conversion of carotene to vitamin $A$ is disturbed, or if the levels of the two blood components are depressed to different extents by the disease process, this ratio should measure the degree of departure from normal relations.

The individual measurements are presented in Tables I to III, and the mean values, standard deviations, and ranges are given in Table IV. Also given in Table IV are similar data on normal adults elsewhere reported (20) and, in addition, unpublished plasma cholesterol values on the same normal subjects. Measurements in certain patients with Laennec's cirrhosis (numbers 4, 28, and 41) appear in both Tables I and II due to changes in their clinical condition.

In determining the statistical significance of the data,

TABLE I

Plasma vitamin $A$, carotenoid, and cholesterol, and dark adaptation time in patients with decompensated Laennec's cirrhosis

When the value recorded represents an average, the number of observations is indicated in parenthesis.

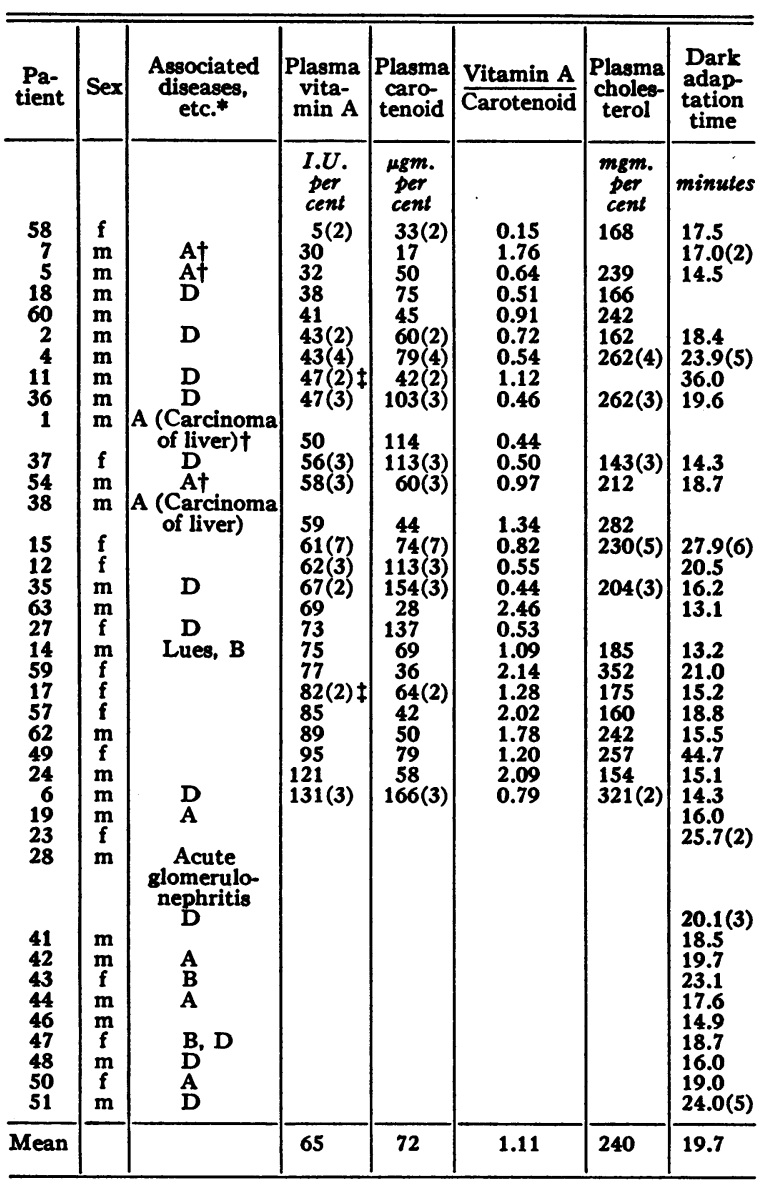

* A denotes autopsy, B biopsy, and D died, no autopsy. † See Table V for vitamin A and carotenoid content of the liver.

$\ddagger$ Fever may have contributed to the low value. the methods and tables of R. A. Fisher (24) were employed. A difference between two mean values was considered significant if the probability of such a difference arising by chance was found to be less than 0.05 ( 1 chance in 20).

\section{RESULTS}

Decompensated cirrhosis. Table I shows individual measurements of 38 patients with decompensated Laennec's cirrhosis. These values may be compared with the range of normal values given in Table IV. In 24 of 26 cases the vitamin A level is below the lowest normal value; in 13 of 26 cases the carotenoid level is below the lowest normal value; in 26 of 33 cases the dark adaptation time is above the highest normal value; and in 8 of 26 cases the A/C ratio is below lowest normal and in no cases above highest normal.

Compensated cirrhosis. Table II shows individual measurements of 27 patients with compensated Laennec's cirrhosis. These are similar in most respects to those of Table I, but show less striking deviations from the normal. Moreover, in contrast to a tendency to low values shown by the decompensated cases, the $\mathrm{A} / \mathrm{C}$ ratio is below normal in only 3 of 23 cases, while in 4 it is above normal. These quantitative differences between groups I and II imply that the degree of change in such measurements may afford a crude index to the degree of liver dysfunction.

Hospital controls. Table III presents data obtained from 38 patients having 25 miscellaneous diseases. In these patients a majority of the values are within the normal range. Of the abnormal values about one-half represent minimal deviations from the normal. It may be noted that the plasma cholesterol level is abnormally high in certain instances, as in the case of nephrosis. On this account the mean value for the entire group is above normal, although not significantly so (Table IV).

Table IV compares the ranges, and mean values of the 3 groups of patients with those for corresponding measurements in normal persons. In calculating the mean dark adaptation time for the hospital controls there were included additional measurements of 40 patients having 16 miscellaneous diseases. Statistically significant differences exist between all the mean values in each column of Table IV except those designated by asterisks. 
TABLE II

Plasma vitamin A, carotenoid, and cholesterol, and dark adaptation time in patients with compensated Laennec's cirrhosis

When the value recorded represents an average, the number of observations is indicated in parenthesis.

\begin{tabular}{|c|c|c|c|c|c|c|c|}
\hline Patient & Sex & Associated diseases, etc.* & $\underset{\text { vitamin A }}{\text { Plasma }}$ & $\begin{array}{c}\text { Plasma } \\
\text { carotenoid }\end{array}$ & $\frac{\text { Vitamin A }}{\text { Carotenoid }}$ & $\begin{array}{c}\text { Plasma } \\
\text { cholesterol }\end{array}$ & $\begin{array}{l}\text { Dark adap- } \\
\text { tation time }\end{array}$ \\
\hline $\begin{array}{r}52 \\
8 \\
30 \\
13 \\
16 \\
\\
20 \\
61 \\
32 \\
29 \\
28 \\
3 \\
26 \\
33 \\
31 \\
9 \\
4 \\
25 \\
56 \\
39 \\
41 \\
53 \\
34 \\
10 \\
21 \\
\\
22 \\
40 \\
45\end{array}$ & $\begin{array}{l}\mathbf{m} \\
\mathbf{m} \\
\mathbf{f} \\
\mathbf{m} \\
\mathbf{f} \\
\mathbf{m} \\
\mathbf{f} \\
\mathbf{f} \\
\mathbf{f} \\
\mathbf{m} \\
\mathbf{m} \\
\mathbf{m} \\
\mathbf{f} \\
\mathbf{m} \\
\mathbf{m} \\
\mathbf{m} \\
\mathbf{f} \\
\mathbf{m} \\
\mathbf{m} \\
\mathbf{m} \\
\mathbf{m} \\
\mathbf{f} \\
\mathbf{m} \\
\mathbf{m} \\
\mathbf{f} \\
\mathbf{m} \\
\mathbf{f}\end{array}$ & $\begin{array}{l}\text { Myxedema } \\
\text { At+ } \$ \\
\text { Chronic glomerulo- } \\
\text { nephritis } \\
\text { Polyneuritis } \\
\text { Diabetes mellitus } \\
\text { D\& } \\
\text { Polyneuritis } \\
\text { Polyneuritis } \\
\text { Polyneuritis } \\
\text { Polyneuritis } \\
\text { Polyneuritis } \\
\text { B } \\
\text { Polyneuritis }\end{array}$ & $\begin{array}{c}\text { I.U. per cent } \\
5(21) \\
24 \\
47 \\
72(3) \\
75(7) \\
97 \ddagger \\
98 \\
109 \\
115(2) \\
117 \\
113(12) \\
141 \\
143(2) \\
146(2) \\
151(3) \\
152 \\
153(4) \\
164 \\
166 \\
167 \\
170 \\
175 \\
181\end{array}$ & $\begin{array}{c}\text { Mgm. per cent } \\
170(21) \\
179 \\
58 \\
108(3) \\
247(3) \\
\\
108 \\
40 \\
108 \\
25(2) \\
87 \\
169(12) \\
58 \\
79(2) \\
31(2) \\
122(3) \\
48 \\
51(4) \\
79 \\
47 \\
8 \\
62 \\
28 \\
112\end{array}$ & $\begin{array}{l}0.30 \\
0.13 \\
0.81 \\
0.67 \\
0.30 \\
\\
0.90 \\
2.45 \\
1.01 \\
4.60 \\
1.34 \\
0.79 \\
2.43 \\
1.81 \\
4.71 \\
1.25 \\
3.17 \\
3.00 \\
2.08 \\
3.53 \\
20.90 \| \\
2.74 \\
6.25 \\
1.62\end{array}$ & $\begin{array}{l}\text { mgm. per cent } \\
245(21) \| \\
207 \\
185 \\
195 \\
383(17) \| \\
\\
238 \\
197 \\
556 \| \\
271(8) \\
\\
285 \\
256(2) \\
309(2) \\
312 \\
235(2) \\
232 \\
386 \\
\\
278 \\
250\end{array}$ & $\begin{array}{l}\text { minutes } \\
27.3 \\
11.3 \\
18.7(4) \\
18.5(2) \\
24.0 \\
14.4 \\
21.1(12) \\
14.2 \\
16.2 \\
10.4\end{array}$ \\
\hline Mean & & & 122 & 88 & 2.08 & 271 & 17.3 \\
\hline
\end{tabular}

* A denotes autopsy, B biopsy, and D died, no autopsy.

+ See Table V for vitamin $A$ and carotenoid content of liver.

$¥$ Fever may have contributed to the low value.

Death not attributable to Laennec's cirrhosis.

Omitted in computing the mean. The cholesterol values were omitted because these patients had diseases known to induce abnormally high blood cholesterol levels.

The mean values (Table IV) of the plasma vitamin $\mathrm{A}$ and carotenoid, and of the dark adaptation time, grow progressively more abnormal in the following order of the groups: normal controls, hospital controls, compensated cirrhotics, and decompensated cirrhotics. Thus all three variables are influenced in the same direction by the presence and by the severity of Laennec's cirrhosis.

The most striking departure from normal and from the hospital controls is exhibited by the plasma vitamin A level of the decompensated cirrhotics (Table IV). The mean value of the plasma vitamin A for this group is only $1 / 3$ of normal compared with $1 / 2$ of normal for the carotenoid level and $1 \frac{1}{2}$ times above normal for the dark adaptation time. Moreover, 92 per cent of the vitamin $\mathrm{A}$ values are outside of the normal range compared with 50 per cent of the carotenoid, 31 per cent of the $\mathrm{A} / \mathrm{C}$ ratio, and 79 per cent of the dark adaptation time values. The distribution of plasma vitamin A values within each of the 4 groups of subjects is shown graphically in Figure 1 .

The plasma vitamin A level clearly differentiates the compensated from the decompensated group of cirrhotic patients, the mean vitamin A level of the latter group being only $1 / 2$ that of the former. Although the mean carotenoid level is lower and the mean dark adaptation time higher in the decompensated than in the compensated group, the differences are relatively small and lack statistical significance (Table IV).

The mean plasma $\mathrm{A} / \mathrm{C}$ ratio of the decompen- 
sated cirrhotics is significantly lower than those hospital control groups. This suggests that in of the other 3 groups. Thirty-one per cent of the values are below the lowest normal compared the patients with decompensated cirrhosis the with 13 per cent each for the compensated and conversion of carotene to vitamin $\mathrm{A}$ is impaired. The abnormally high mean $\mathrm{A} / \mathrm{C}$ ratio of the com-

TABLE III

Plasma vitamin $A$, carotenoid, and cholesterol, and dark adaptation time in patients with various diseases other than Laennec's cirrhosis

When the value represents an average, the number of observations is indicated in parenthesis.

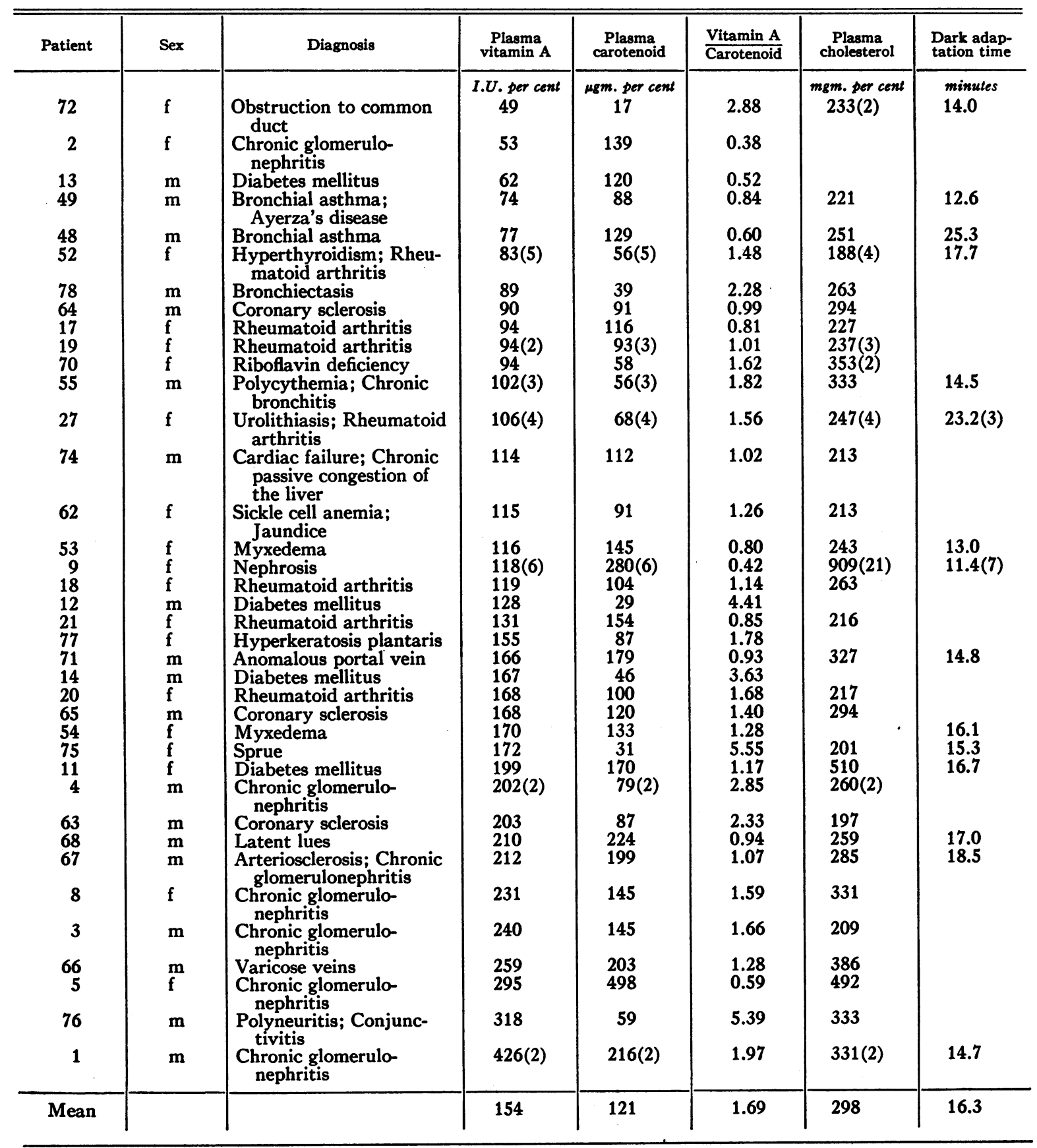


TABLE IV

Mean values and standard deviations of the measurements recorded in Tables $I$ to III

For comparison, similar data obtained in normal controls are also given.

\begin{tabular}{|c|c|c|c|c|c|c|}
\hline \multicolumn{2}{|c|}{ Diagnosis } & Plasma vitamin A & Plasma carotenoid & $\frac{\text { Vitamin A }}{\text { Carotenoid }}$ & Plasma cholesterol & $\begin{array}{l}\text { Dark adap- } \\
\text { tation time }\end{array}$ \\
\hline $\begin{array}{l}\text { I. Decompensated } \\
\text { Laennec's } \\
\text { cirrhosis }\end{array}$ & $\begin{array}{l}\text { Mean....... } \\
\text { S.D........ } \\
\text { Range..... } \\
\text { Number... }\end{array}$ & $\begin{array}{c}\text { I.U. per cent } \\
65 \\
28 \\
5-131 \\
26\end{array}$ & $\begin{array}{c}\text { Agm. per cent } \\
72^{*} \\
35 \\
17-166 \\
26\end{array}$ & $\begin{array}{c}1.11 \\
0.67 \\
0.15-2.64 \\
26\end{array}$ & $\begin{array}{c}\text { mgm. per cent } \\
240^{*} \\
55 \\
143-352 \\
20\end{array}$ & $\begin{array}{c}\text { minutes } \\
19.7^{*} \\
6.1 \\
13.1-44.7 \\
33\end{array}$ \\
\hline $\begin{array}{l}\text { II. Compensated } \\
\text { Laennec's } \\
\text { cirrhosis }\end{array}$ & $\begin{array}{l}\text { Mean....... } \\
\text { S.D......... } \\
\text { Range..... } \\
\text { Number... }\end{array}$ & $\begin{array}{c}122 \\
34 \\
5-181 \\
23\end{array}$ & $\begin{array}{l}88^{*} \\
57 \\
8-247 \\
23\end{array}$ & $\begin{array}{c}2.08 \\
1.43 \\
0.03-6.25 \\
23\end{array}$ & $\begin{array}{c}271^{*} \\
47 \\
185-386 \\
15\end{array}$ & $\begin{array}{c}17.3^{*} \\
4.6 \\
10.4-27.3 \\
16\end{array}$ \\
\hline $\begin{array}{l}\text { III. Miscellaneous } \\
\text { diseases }\end{array}$ & $\begin{array}{l}\text { Mean....... } \\
\text { S.D......... } \\
\text { Range..... } \\
\text { Number... }\end{array}$ & $\begin{array}{c}154 \\
77 \\
49-426 \\
38\end{array}$ & $\begin{array}{c}121 \\
53 \\
17-498 \\
38\end{array}$ & $\begin{array}{c}1.69^{*} \\
1.24 \\
0.38-5.55 \\
38\end{array}$ & $\begin{array}{c}298^{*} \\
123 \\
188-909 \\
32\end{array}$ & $\begin{array}{c}15.2 \dagger \\
2.9 \\
9.8-25.3 \\
55\end{array}$ \\
\hline Normal & $\begin{array}{l}\text { Mean....... } \\
\text { S.D......... } \\
\text { Range..... } \\
\text { Number... }\end{array}$ & $\begin{array}{c}198 \\
42 \\
109-309 \\
44\end{array}$ & $\begin{array}{c}144 \\
35 \\
64-260 \\
44\end{array}$ & $\begin{array}{c}1.43^{*} \\
0.43 \\
0.64-3.77 \\
44\end{array}$ & $\begin{array}{c}254^{*} \\
45 \\
169-357 \\
41\end{array}$ & $\begin{array}{l}13.1 \\
1.6 \\
9.5-15.0 \\
37\end{array}$ \\
\hline
\end{tabular}

* Statistically significant differences exist between all mean values in each column except those designated by asterisks. † Includes dark adaptation data not listed in Table III, obtained in 40 additional patients having 16 miscellaneous diseases.

pensated group appears to be caused by the less drastic reduction of the plasma vitamin A level in this milder form of the disease, while the carotenoid level is lowered almost to the same extent in both forms.

Patient number 4, for whom there are blood determinations in both the decompensated (Table I) and the compensated (Table II) conditions, provides an illustration of the sensitivity of the vitamin $A$ level and the $A / C$ ratio to changes in the severity of the disease. When decompensated, his vitamin A level was 43 I.U. per cent and his $\mathrm{A} / \mathrm{C}$ ratio 0.54 ; when his condition improved to a point of relatively complete compensation, his vitamin A level rose to 152 I.U. per cent and his $\mathrm{A} / \mathrm{C}$ ratio to 3.17 .

Josephs' observations (25) suggest that reduced plasma vitamin A, carotenoid, and cholesterol levels in blood of low lipid content may be caused in large part by the high fat solubility of these substances. Thus low cholesterol values should be accompanied by proportionately low vitamin A and carotenoid values. However, we have observed only weakly positive correlations between vitamin $A$ and carotenoid blood levels and the blood level of cholesterol. Moreover, Table IV shows that the mean plasma cholesterol levels for the cirrhotic patients and the normal subjects are so nearly identical that it may be said that no reliable differences exist. The conclusion is obvious that the low plasma vitamin $\mathrm{A}$ and carotenoid concentrations found in the cirrhotic patients are not attributable in a significant degree to low total lipid levels in the blood.

Post and Patek (26) have shown that the serum albumin level is correlated with the clinical course of Laennec's cirrhosis. It might be supposed, therefore, that the relation here observed between the plasma vitamin A level and the clinical severity of the disease is related to changes in the concentration of the serum albumin. If this were the case, a high positive correlation should be found between the blood vitamin $\mathrm{A}$ and albumin levels in patients with other diseases. Upon examination, however, no such relation was observed. Thus the blood vitamin A-albumin ratio for 10 patients in the group of hospital controls varied from 35 to 91 , whereas this ratio should be constant were there a linear relation between the variables. Moreover, 4 of these 10 patients had abnormally low serum albumin values of 2.0 , 2.2, 3.3, and 3.5 grams per cent, although their 


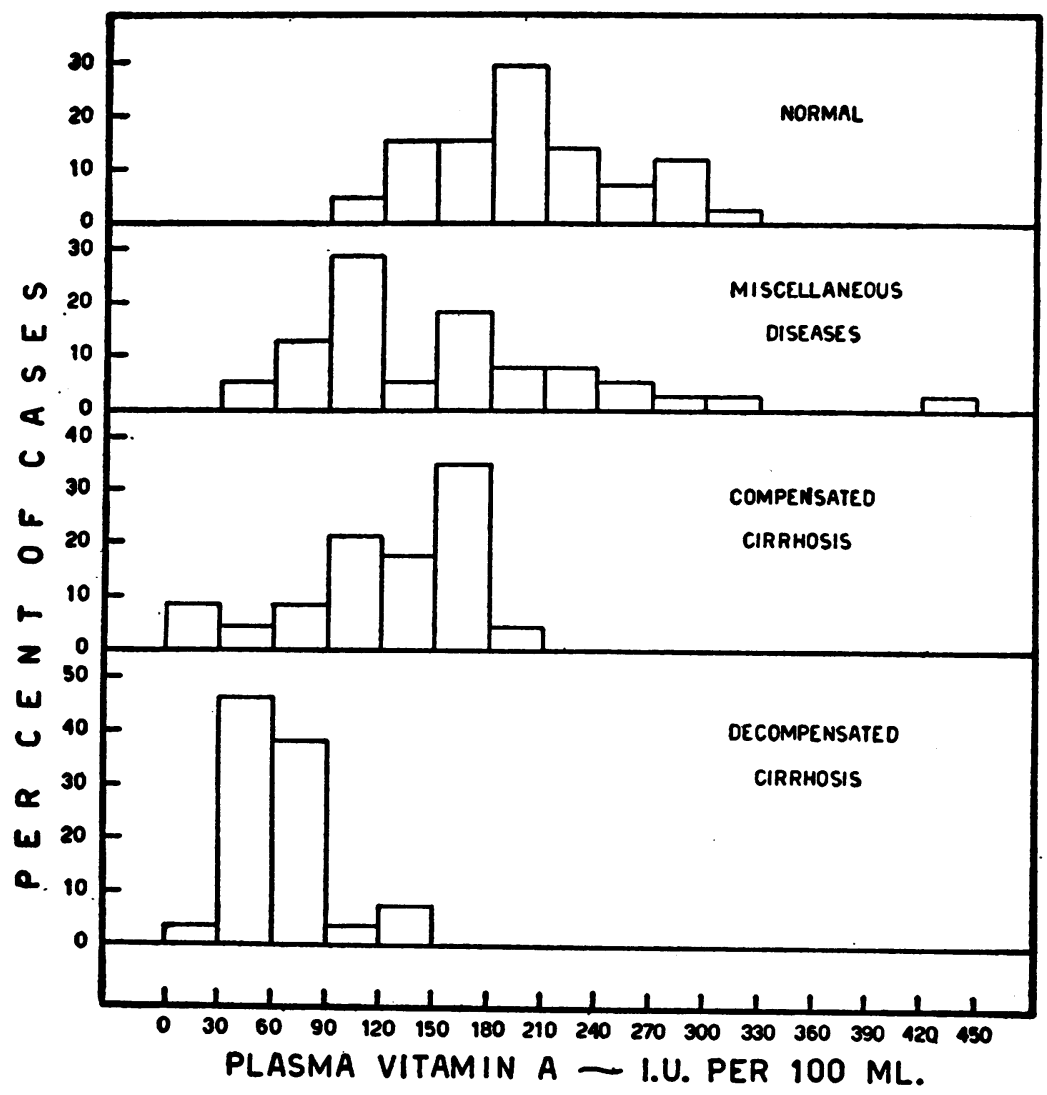

Fig. 1. Percentage Distribution of Plasma Vitamin a Values in Class INTERVALS OF 30 I.U. PER CENT FOR THE 4 GROUPS OF SUBJECTS

plasma vitamin A values were well within the normal limits, being respectively $118,170,295$, and 202 I.U. per cent.

$V$ itamin $A$ and carotenoid content of cirrhotic livers. Table $\mathrm{V}$ presents the vitamin $\mathrm{A}$ and carotenoid concentrations found in 6 cirrhotic livers at autopsy, 5 being from patients in the present series. The mean vitamin A concentration of 124 I.U. per gram, carotenoid concentration of $4.3 \mu \mathrm{gm}$. per gram, and A/C ratio of 36 are in close agreement with corresponding values reported by Ralli et al. (7) for the livers of 15 persons who died of cirrhosis of the liver. These workers found mean values of 137 I.U. per gram for vitamin A, $5.7 \mu \mathrm{gm}$. per gram for carotenoid, and 31 for the $A / C$ ratio. Their findings for 23 normal persons killed in accidents may therefore be compared with the present values obtained in cirrhotic livers. The mean values for these normal livers were 766 I.U. per gram for vitamin A,
$13.6 \mu \mathrm{gm}$. per gram for carotenoid, and 74 for the $\mathrm{A} / \mathrm{C}$ ratio ( 7$)$.

\section{DISCUSSION}

It is significant that of the 12 patients with compensated cirrhosis for which there are visual as well as blood measurements, 3 have abnormal dark adaptation times although the concentrations of the blood components are normal. While two of the abnormal dark adaptation values are not particularly high (16.2 minutes), one is strikingly abnormal (21.1 minutes). To understand this phenomenon it is necessary to recall the evidence $(3,4,20,27,28)$ that abnormal dark adaptation of the type encountered in Laennec's cirrhosis, i.e., delayed, with or without elevation of the final threshold, is an index of faulty utilization of vitamin $A$ by the retina. This delayed type of adaptation, involving a disturbance in the kinetics of the retinal process (presumably a slowing of 
the rate of visual purple regeneration), is to be distinguished from the simple elevation of the visual threshold observed in experimental vitamin A deficiency (12). Apparently, the liver normally contributes to the functioning of the visual mechanism independently of its rôle as the principal vitamin A depot. Thus an abnormally high dark adaptation time in a patient with Laennec's cirrhosis may be entirely consistent with concomitant normal vitamin $\mathrm{A}$ and carotenoid levels.

Of more frequent occurrence among patients with cirrhosis is an abnormal plasma vitamin A or carotenoid level with a normal dark adaptation time, viz., 5 of 21 decompensated and 3 of 12 compensated cases. This indicates the presence in these patients of vitamin A deficiency per se which is presumably not sufficiently severe or prolonged to raise the dark adaptation time to an abnormal level. It likewise shows the absence in these subjects of the faulty utilization of vitamin A by the retina, characteristic of Laennec's cirrhosis $(3,4)$.

Although these patients did not have jaundice or diarrhea at the time of observation, it is possible that the low values for plasma vitamin $\mathrm{A}$ are related in part to malabsorption from the intestinal tract. It seems improbable that this is the only factor involved, since there is a correlation between the degree of vitamin A deficiency and the apparent degree of liver incompetence. Previous studies $(3,4)$ on dark adaptation in patients with Laennec's cirrhosis also showed changes that were not explicable on the basis of malabsorption alone.

In addition to those mentioned, there are a number of other factors known to exert independent effects upon the plasma vitamin A level or the dark adaptation function: alcohol mobilizes vitamin $A$ in the blood (30) and elevates the visual threshold (31); febrile conditions, as well as reduced vitamin $\mathrm{A}$ intake, may depress the blood vitamin A level without measureably influencing the visual threshold $(17,18,29)$; thyroid extract and $\alpha$-dinitrophenol, in certain conditions, simultaneously increase the speed and extent of dark adaptation and depress the blood level of vitamin A (27), glucose lowers the visual threshold when the latter is elevated by anoxemia (32); retinitis pigmentosa and optic nerve atrophy are
TABLE $v$

Concentration of vitamin $A$ and carotenoid in cirrhotic livers

\begin{tabular}{|c|c|c|c|}
\hline Patient & Vitamin A & Carotenoid & $\frac{\text { Vitamin A }}{\text { Carotenoid }}$ \\
\hline $\begin{array}{r}1^{*} \\
5 \\
7 \\
8 \\
54 \\
64\end{array}$ & $\begin{array}{c}I . U . \text { per gram } \\
305 \\
35 \\
121 \\
161 \\
102 \\
21\end{array}$ & $\begin{array}{c}\text { Mgm. per gram } \\
3 \\
2 \\
6 \\
10 \\
3 \\
2\end{array}$ & $\begin{array}{r}102 \\
18 \\
20 \\
16 \\
51 \\
11\end{array}$ \\
\hline $\begin{array}{l}\text { Mean } \\
\text { Standard } \\
\text { deviation }\end{array}$ & $\begin{array}{l}124 \\
121\end{array}$ & $\begin{array}{l}4.3 \\
3.2\end{array}$ & $\begin{array}{l}36 \\
35\end{array}$ \\
\hline
\end{tabular}

* Primary cancer of liver present.

associated with high visual thresholds (31), although neither condition is attributable to vitamin A deficiency. Thus the relation between vitamin A supply and visual sensation is complicated by numerous remote as well as proximal factors whose contributions must be estimated for a precise evaluation of the end result.

The present evidence renders it highly probable that the abnormal values of the vitamin $A$ and carotenoid levels in the blood and liver, and of the dark adaptation time, observed in patients with Laennec's cirrhosis, are attributable primarily to the presence of cirrhosis per se rather than to any combination of the several extraneous factors enumerated above.

\section{SUMMARY AND CONCLUSIONS}

1. The dark adaptation time and the concentration of vitamin A and of total carotenoid in the blood plasma were determined in 49 patients with Laennec's cirrhosis and in 38 patients with various other diseases. The vitamin $\mathrm{A}$ and carotenoid concentrations were also determined in 6 cirrhotic livers. The vitamin A intake was controlled and the cirrhotic patients were free of jaundice, of diarrhea and, in most instances, of fever.

2. Compared with the mean normal level of 198 international units of vitamin A per $100 \mathrm{ml}$. of plasma, the mean values for the patients were as follows: decompensated cirrhosis, 65 I.U. per cent; compensated cirrhosis, 122 I.U. per cent; miscellaneous diseases, 154 I.U. per cent. Ninetytwo per cent of the patients with decompensated cirrhosis had values below the lowest normal. 
3. Compared with the mean normal level of 144 micrograms of total carotenoid per $100 \mathrm{ml}$. of plasma, the mean values for the patients were as follows: decompensated cirrhosis, $72 \mu \mathrm{gm}$. per cent; compensated cirrhosis, $88 \mu \mathrm{gm}$. per cent; miscellaneous diseases, $121 \mu \mathrm{gm}$. per cent. Fifty per cent of the patients with decompensated cirrhosis had values below the lowest normal.

4. Compared with the mean normal dark adaptation time of 13.1 minutes, the mean values for the patients were as follows: decompensated cirrhosis, 19.7 minutes; compensated cirrhosis, 17.3 minutes; miscellaneous diseases, 15.2 minutes. Seventy-nine per cent of the patients with decompensated cirrhosis had values above the highest normal.

5. Compared with the mean normal concentrations of 766 I.U. per gram of vitamin A and $13.6 \mu \mathrm{gm}$. per gram of carotenoid, 6 cirrhotic livers had concentrations of 124 I.U. per gram of vitamin $A$ and $4.3 \mu \mathrm{gm}$. per gram of carotenoid.

6. It is concluded that (1) the incidence and the degree of vitamin A deficiency, as measured by the level of vitamin $A$ and of carotenoid in the blood and liver, and by the dark adaptation time, are greater in Laennec's cirrhosis than in the mixed group of diseases used as controls in the present study; (2) among these three variables the one most markedly influenced by the presence and by the severity of Laennec's cirrhosis is the blood vitamin A level, which appears to be a crude index of the severity of the disease process.

\section{BIBLIOGRAPHY}

1. Breusch, F., and Scalabrino, R., Die quantitativen Verhältnisse der Leberlipoide. Ztschr. f. d. ges. exper. Med., 1934, 94, 569.

2. Lasch, F., Uber den Vitamin A-Spiegel im Blute bei Leberkrankheiten. Klin. Wchnschr., 1938, 17, 1107.

3. Haig, C., Hecht, S., and Patek, A. J., Jr., Vitamin $A$ and rod-cone dark adaptation in cirrhosis of the liver. Science, 1938, 87, 534.

4. Patek, A. J., Jr., and Haig, C., The occurrence of abnormal dark adaptation and its relation to vitamin A metabolism in patients with cirrhosis of the liver. J. Clin. Invest., 1939, 18, 609.

5. Rubegni, R., Il contenuto in vitamin A e in carotina del siero umano in varie condizioni pathologiche. Policlinico (sez. med.), Rome, 1939, 46, 565.

6. Woo, T. T., and Chu, F. T., Vitamin A content of livers of chinese infants, children and adults. Chinese J. Physiol., 1940, 15, 83.

7. Ralli, E. P., Papper, E., Paley, K., and Baumann, E., Vitamin $A$ and carotene content of human liver in normal and in diseased subjects : an analysis of one hundred and sixteen human livers. Arch. Int. Med., 1941, 68, 102.

8. Bajardi, G., and Galeone, A., La cecità notturna quale sintomo di malattia epatica. Policlinico (sez. prat.), 1941, 48, 193.

9. Ralli, E. P., Baumann, E., and Roberts, L. B., The plasma levels of vitamin $A$ after ingestion of standard doses: studies in normal subjects and patients with cirrhosis of the liver. J. Clin. Invest., 1941, 20, 709.

10. McCoord, A. B., and Luce-Clausen, E. M., The storage of vitamin $A$ in the liver of the rat. J. Nutrition, 1934, 7, 557.

11. Lewis, J. M., and Haig, C., Vitamin A requirements in infancy as determined by dark adaptation. J. Pediat., 1939, 15, 812.

12. Hecht, S., and Mandelbaum, J., Dark adaptation and experimental human vitamin A deficiency. Am. J. Physiol., 1940, 130, 651.

13. Lewis, J. M., Bodansky, O., Falk, K. G., and McGuire, G., Relationship of vitamin A blood level in the rat to vitamin $\mathrm{A}$ intake and to liver storage. Proc. Soc. Exper. Biol. and Med., 1941, 46, 248.

14. Horton, P. B., Murrill, W. A., and Curtis, A. C., Vitamin $A$ and carotene. I. The determination of vitamin $A$ in the blood and liver as an index of vitamin A nutrition of the rat. J. Clin. Invest., 1941, 20, 387.

15. Crimm, P. D., and Short, D. M., Vitamin A content of human liver in tuberculosis. Ann. Int. Med., 1939, 13, 61.

16. Breese, B. B., and McCoord, A. B., Vitamin A absorption in catarrhal jaundice. J. Pediat., 1940, 16, 139.

17. Clausen, S. W., and McCoord, A. B., The carotenoids and vitamin A of the blood. J. Pediat., 1938, 13, 635.

18. Lewis, J. M., Bodansky, O., and Haig, C., Level of vitamin $A$ in the blood as an index of vitamin $A$ deficiency in infants and in children. Am. J. Dis. Child., 1941, 62, 1129.

19. Patek, A. J., Jr., and Post, J., Treatment of the liver by a nutritious diet and supplements rich in vitamin B complex. J. Clin. Invest., 1941, 20, 481.

20. Haig, C., and Patek, A. J., Jr., The relation between dark adaptation and the level of vitamin $A$ in the blood. (To be published.)

21. Haig, C., and Post, J., Vitamin A concentration in rat liver during recovery from $\mathrm{CCl}_{4}$ cirrhosis. Proc. Soc. Exper. Biol. and Med., 1941, 48, 710.

22. Bloor, W. R., Pelkin, K. F., and Allen, D. M., Determination of fatty acids (and cholesterol) in small amounts of blood plasma. J. Biol. Chem., 1922, 52, 191. 
23. Daniel, E. P., and Munsell, H. E., Vitamin content of foods. U. S. Dept. of Agric. misc. public. 275, June, 1937.

24. Rider, P. R., An Introduction to Modern Statistical Methods. John Wiley \& Sons, New York, 1939.

25. Josephs, H. W., Studies in vitamin A; relation of vitamin $A$ and carotene to serum lipids. Bull. Johns Hopkins Hosp., 1939, 65, 112.

26. Post, J., and Patek, A. J., Jr., Serum proteins in cirrhosis of the liver. I. Their relation to prognosis and to the formation of ascites. Arch. Int. Med., 1942, 69, 67.

27. Haig, C., Vitamin A and the rates of adaptation of the eye to light and darkness. Anat. Rec., 1940, 78, suppl., 163.

28. Patek, A. J., Jr., and Haig, C., Effect of administration of thyroid extract and of a-dinitrophenol upon dark adaptation. Proc. Soc. Exper. Biol. and Med., 1941, 46, 180.

29. Bodansky, O., Lewis, J. M., and Haig, C., The comparative value of the blood plasma vitamin A concentration and the dark adaptation as a criterion of vitamin A deficiency. Science, 1941, 94, 370.

30. Clausen, S. W., Baum, W. S., McCoord, A. B., Rydeen, J. A., and Breese, B. B., Mobilization of vitamin A from its stores in the tissues by ethyl alcohol. Science, 1940, 91, 318.

31. Mandelbaum, J., Dark adaptation. Some physiologic and clinical considerations. Arch. Ophth., New York, 1941, 26, 203.

32. McFarland, R. A., and Evans, J. M., The effects of variations in the concentration of oxygen and of glucose on dark adaptation. J. Gen. Physiol., 1940, 24, 69. 